\title{
Discontinuous Precipitation in Aged Welded Joints of High Cr-Ni Superalloy
}

\author{
J.C. Spadotto ${ }^{1}$ and I.G. Solórzano ${ }^{1}$ \\ ${ }^{1 .}$ Department of Chemical and Materials Engineering, PUC-Rio, Rio de Janeiro, Brazil
}

Welded joints of multicomponent alloys when submitted to high temperatures close to operating conditions are very susceptible to grain boundary precipitation, thereby reducing both corrosion resistance and mechanical properties [1]. We focus our attention here on discontinuous precipitation (DP) phenomenon taking place in a high-performance austenitic alloy, denominated alloy 33 because of the almost equal content of the elements $\mathrm{Fe}, \mathrm{Ni}$ and $\mathrm{Cr}$ (wt. \%) of 32.75Cr-32.53Fe-31.35Ni1.49Mo-0.54Cu-0.4N-0.012C-0.63Mn-0.30Si. The material was submitted to a Gas Tungsten Arc Welding (GTAW) process on both sides of the base metal followed by direct-aging at $700{ }^{\circ} \mathrm{C}$ for different times intervals. The fill metal used in the welding process was the same as the base metal.

Light optical micrograph (LOM) of Figure 1A shows the overall microstructure of the as-welded junction: with the welded metal zone (WMZ) at upper right, the base metal (BM) at low left and the heat-affected zone (HAZ) at the interface. The BM consists of a fully austenitic matrix with equiaxial grains and annealing twins, while the WMZ show columnar grains with cellular substructures and free of twins. It is noticed the solidification of the weld metal epitaxial with the base metal grains. This type of growth maintains the same crystalline orientation of the grains of the $\mathrm{BM}$, favoring the continuity of the microstructure at the interface HAZ/WMZ. The SEM image shown in Figure 1B corresponds to a typical microstructure of a welded junction after direct-aging at $700{ }^{\circ} \mathrm{C}$ for $100 \mathrm{~h}$. In this low magnification SEM image, it is clear that the aging treatment has promoted grain boundary precipitation in the conventional and discontinuous fashions. The later have generated well developed DP colonies, as the one pointed by the arrows at the HAZ and, more prominently, at the WMZ. Analysis of the precipitation phenomena at the grain boundaries revealed that the DP product consists of alternated lamellae of a precipitated (equilibrium) phase and a depleted matrix, both growing in a cooperative fashion. While DP phenomenon has been reported to occur in numerous binary and multicomponent systems [2], the occurrence of DP in aged weld metal products has not been reported.

SEM image shown in Figure $2 \mathrm{~A}$ presents a complex DP colony at a grain boundary in the WMZ upon direct-aging at $700{ }^{\circ} \mathrm{C}$ for $100 \mathrm{~h}$. Figure $2 \mathrm{~B}$ is a higher magnification Field emission SEM micrograph of the boxed area of Fig 2A, showing in more detail a DP reaction front where the precipitates appear in different morphologies, not only lamellar, and resulting from a growth process in different direction. In fact, when conducting X-ray elemental mapping on this same boxed area, different phases composition are revealed in this DP colony. While Ni and Fe intensities indicate that these two elements are equally distributed in the supersaturated and in the DP colony depleted matrix, $\mathrm{Cr}$ and $\mathrm{C}$ constitute a DP carbide phase with the lamellar morphology and Si and Mo are concentrated in a different phase, constituting a novel finding in the context of DP phenomenon. Current investigation is focused on the complete identification of the above-mentioned phases in terms of composition, crystallography and orientation relationships [3].

\section{References:}

[1] K. Guan et al, Nucl. Eng. Des. 235(23) (2005), p. 2485.

[2] I. Manna et al, Int. Mater. Rev. 46(2) (2001), p. 53.

[3] The authors acknowledge are grateful to CBPF for the access to the LabNano Electron

Microscopy facilities and to the Brazilian Funding agencies CAPES and CNPq. 

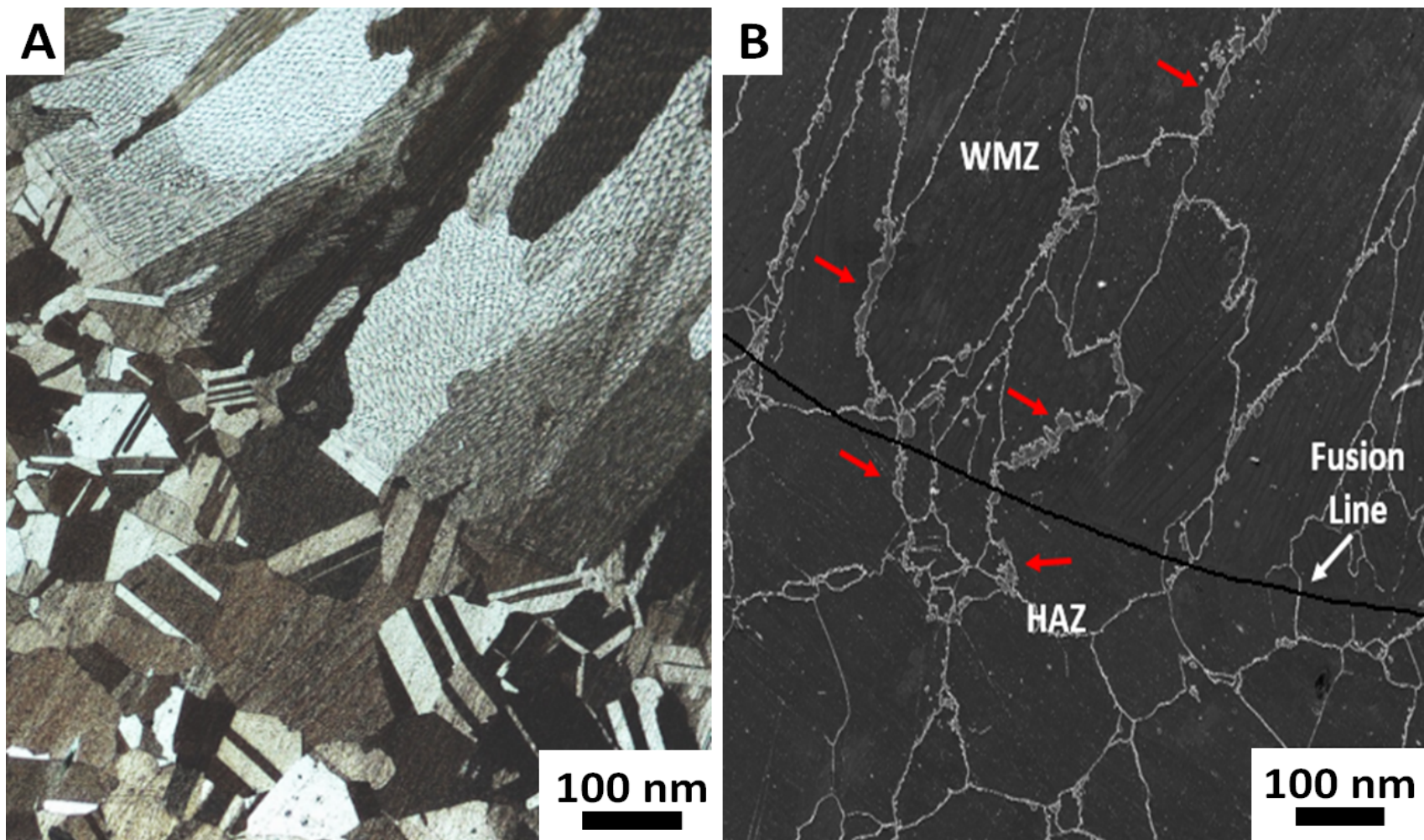

Figure 1. (A) LOM image of welded joint of alloy 33 in the post welding condition showing the interface HAZ/WMZ; (B) SEM image of welded joint resulting from direct-aging at $700{ }^{\circ} \mathrm{C}$ for $100 \mathrm{~h}$. Red arrows indicate DP colonies in both heat-affected zone (HAZ) and welded metal zone (WMZ).

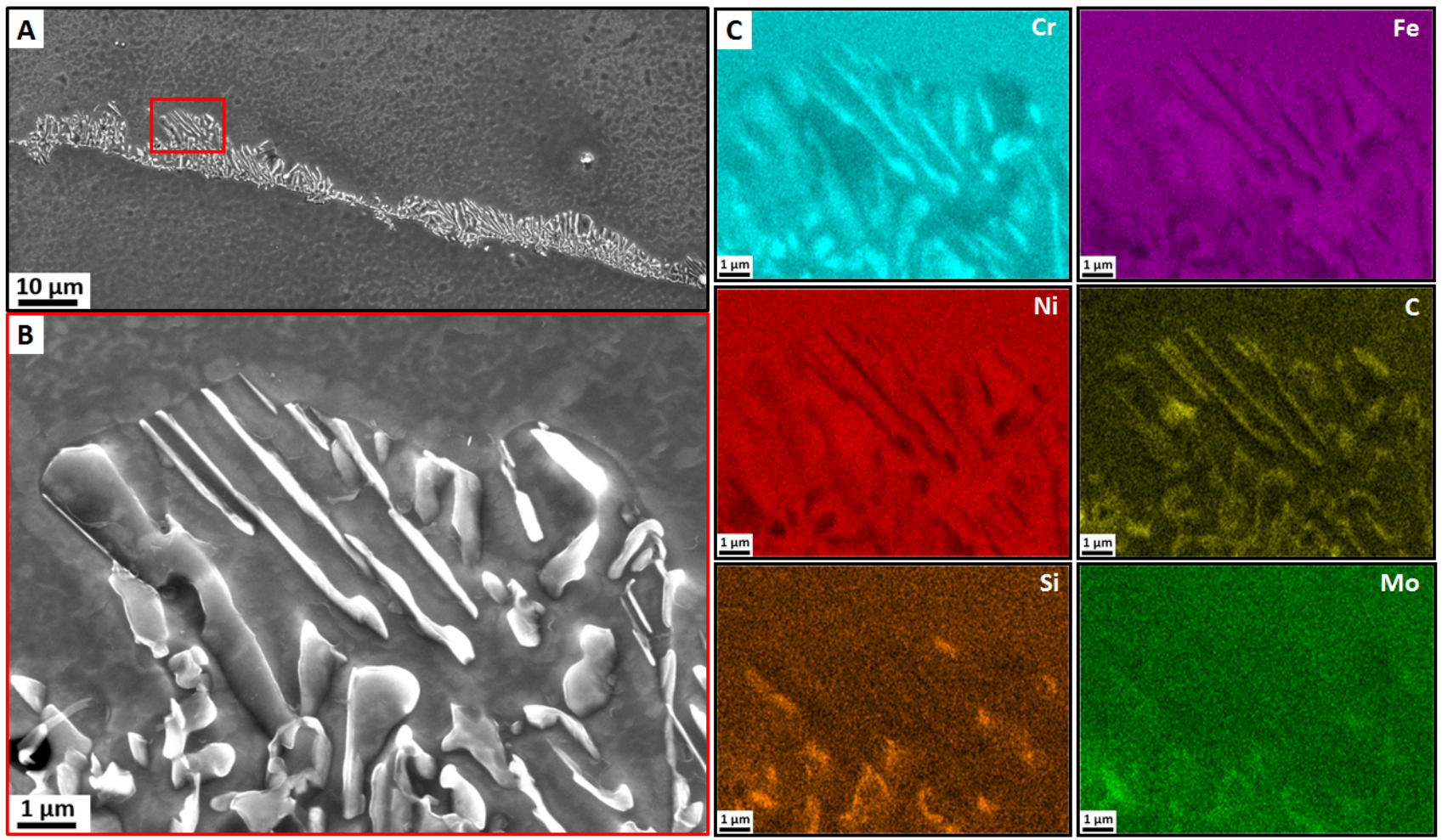

Figure 2. (A) SEM image of welded joint resulting from direct-aging at $700{ }^{\circ} \mathrm{C}$ for $100 \mathrm{~h}$; (B) part of the PD colony indicated by red box in (A); (C) XEDS elemental maps show the degree of partition of different substitutional elements $(\mathrm{Cr}, \mathrm{Fe}, \mathrm{Ni}, \mathrm{Si}, \mathrm{Mo})$ and also interstitial $\mathrm{C}$, identifying different phases in the same DP colony. 